\title{
Acute Atrial Fibrillation During Dengue Hemorrhagic Fever
}

\author{
Henrique Horta Veloso, João Anísio Ferreira Júnior, \\ Joyce Morgana Braga de Paiva, Júlio Faria Honório, \\ Nancy C. Junqueira Bellei and Angelo Amato Vincenzo de Paola
}

VotCor-Department of Cardiology, Hospital of Venerável Ordem Terceira da Penitência, Rio de Janeiro, RJ, Brazil

\begin{abstract}
Dengue fever is a viral infection transmitted by the mosquito, Aedes aegypti. Cardiac rhythm disorders, such as atrioventricular blocks and ventricular ectopic beats, appear during infection and are attributed to viral myocarditis. However, supraventricular arrhythmias have not been reported. We present a case of acute atrial fibrillation, with a rapid ventricular rate, successfully treated with intravenous amiodarone, in a 62-year-old man with dengue hemorrhagic fever, who had no structural heart disease.
\end{abstract}

Key Words: Atrial fibrilation, dengue, arrhythmia.

Dengue fever is caused by an arbovirus, of the gender Flavivirus. Its incidence has increased in tropical areas, where the main vector, Aedes aegypti (Linnaeus), has spread due to unplanned urbanization and lack of effective controls [1]. In Brazil, there has been an increase in the frequency of epidemics and the geographic expansion of both the mosquito vector and the viruses [2].

Cardiac manifestations of dengue infection are uncommon, but cardiac rhythm disorders, such as atrioventricular blocks $[3,4]$ and ectopic ventricular beats [5], have been reported during episodes of dengue hemorrhagic fever. Most of them are asymptomatic and have a benign coarse, being selflimiting, with spontaneous resolution of infection. They have been attributed to viral myocarditis, but the exact mechanism has not been definitively elucidated.

Atrial fibrillation is the most common type of sustained cardiac arrhythmia in clinical practice, and it is often associated with structural heart disease [6,7]. However, this arrhythmia has not been reported during dengue fever.

Received on 23 January 2003; revised 20 June 2003. Address for correspondence: Dr. Henrique Horta Veloso. Rua Lopes Quintas 344 / 106 bloco 1, Jardim Botânico. Zip Code: 22460-010. Rio de Janeiro/RJ, Brazil. Phone: +55 2132058877. Fax:+55 212268 1151. E-mail: hhorta@cardiol.br

The Brazilian Journal of Infectious Diseases 2003;7(6):418-422 (C) 2003 by The Brazilian Journal of Infectious Diseases and Contexto Publishing. All rights reserved.

\section{Case Report}

A 61-year-old man with non-insulin-dependent diabetes mellitus, taking 850mg metformin, twice daily, with no prior cardiovascular disease, was admitted into the hospital in January 2002 with a history of fever, polyarthralgia, persistent vomiting, and malaise, during three days. The patient was not a smoker and had not recently ingested alcohol.

On physical examination, the patient was febrile with a temperature of $39.0^{\circ} \mathrm{C}$, had mild dehydration, an irregular and tachycardic cardiac rhythm, with no murmur, a heart rate of $190 \mathrm{bpm}$, and his arterial blood pressure was $140 / 80 \mathrm{~mm} \mathrm{Hg}$, with no other pathological findings.

A 12-lead electrocardiogram showed atrial fibrillation, with a rapid ventricular rate (Figure 1).

The patient was hospitalized in the coronary care unit and treatment was initiated with paracetamol, intravenous hydration and an anticoagulant $(80 \mathrm{mg}$ subcutaneous enoxiparin, twice daily). Antiarrhythmic therapy was initiated with $450 \mathrm{mg}$ intravenous amiodarone infused during one hour, followed by 900mg over 24 hours.

The patient had a hemoglobin rate of $16.5 \mathrm{~g} / \mathrm{dL}$, a hematocrit of $49.2 \%$, a white blood cell count of $3,100 /$ $\mathrm{mm}^{3}$, and a platelet count of $73,000 / \mathrm{mm}^{3}$ (reduced to $54,000 / \mathrm{mm}^{3}$ on the following day). Other laboratory findings were potassium $3.1 \mathrm{meq} / \mathrm{liter}$, sodium $128 \mathrm{meq} /$ 
liter, magnesium $1.5 \mathrm{mg} / \mathrm{dL}$, calcium $6.6 \mathrm{mg} / \mathrm{dL}$, prothrombin activity $88.7 \%$, INR 1.12, creatine kinase 451U/liter, MB fraction 20U/liter, troponin $<0.5 \mathrm{ng} / \mathrm{mL}$, myoglobin $34.7 \mathrm{ng} / \mathrm{mL}$, lactic dehydrogenase $677 \mathrm{U} /$ liter, creatinine $1.5 \mathrm{mg} / \mathrm{dL}$, urea $33 \mathrm{mg} / \mathrm{dL}$, C-reactive protein $0.64 \mathrm{mg} / \mathrm{dL}$, erythrocyte sedimentation time 38 seconds, serum aspartate transaminase $80 \mathrm{U} / \mathrm{L}$ and serum alanine transaminase $63 \mathrm{U} / \mathrm{L}$.

Transthoracic and transesophageal echocardiograms demonstrated no structural heart disease (left atrium diameter of $39 \mathrm{~mm}$ and left ventricular ejection fraction of 0.73 ), with no intracavitary thrombi.

Due to leuko- and thrombocytopenia, plus hemoconcentration, dengue hemorrhagic fever was suspected [8] and enoxiparin was discontinued. Specific serological tests (IgG and IgM) confirmed the infection.

Twenty-four hours after hospital admission, normal sinus rhythm was restored (Figure 2). Oral amiodarone $600 \mathrm{mg} /$ day was maintained until hospital discharge, which occurred after three days.

The patient was contacted after 10 months and reported no cardiac symptoms or arrhythmia. The patient was taking $200 \mathrm{mg}$ amiodarone daily, according to his physician's orientation.

\section{Discussion}

Some cardiac rhythm disorders have been reported during dengue fever. Recently, Khongphatthallayothin et al. [4] reported two cases of Mobitz type I second degree atrioventricular block during recovery from hemorrhagic dengue; both had spontaneous resolution. Previously, Donegani and Briceño [3] had reported four patients with dengue who developed complete atrioventricular block, which required a permanent pacemaker. Ventricular ectopic beats were also observed by Chuah [5] during dengue infection in patients without electrolytic imbalances. In all these cases, no major cardiac findings were observed in the chest X-rays or the echocardiograms. Though there were no other pathological findings in the heart, the main hypothesis considered for these rhythm disturbances was a subclinical myocarditis caused by the arbovirus.
To the best of our knowledge, no cases of atrial fibrillation related to dengue fever have been reported before. This arrhythmia can occur in patients without underlying heart disease, particularly in thyrotoxicosis and in pulmonary diseases, neither of which were found in our patient. Low potassium levels caused by frequent vomiting could be responsible for the arrhythmia. However, in clinical practice, the observation of atrial fibrillation during hypokalemia is uncommon. Furthermore, if this had been the main cause for this arrhythmia, we would have expected that normal sinus rhythm would be restored with hydroelectrolytic and antithermal therapies, since spontaneous cardioversion without antiarrhythmic therapy can occur in $70 \%$ of the patients with recent-onset atrial fibrillation. The necessity of antiarrhythmic therapy to restore normal sinus rhythm suggests a possible involvement of subclinical myocarditis, despite normal levels of specific cardiac enzymes.

The patient could have had a chronic arrhythmia, since the patient had no specific symptoms, and the febrile infection only increased the atrioventricular conduction and the ventricular rate. Kochiadakis et al. did not observe conversion to a sinus rhythm in 34 patients who had arrhythmias lasting more than 48 hours, despite intravenous amiodarone [9], while in 48 patients with less than 48 hours atrial fibrillation, the cardioversion rate after 24 hours of this therapy reached 83\% [10]. Consequently, we concluded that our patient had an acute arrhythmia.

In this patient, the diagnosis of hemorrhagic dengue fever was suspected based on leukopenia and hemoconcentration, plus dehydration, even though there was no hemorrhagic manifestation, and this diagnosis was confirmed by serological tests. In classical dengue fever, mild thrombocytopenia may occur, but when concomitant hemoconcentration is encountered, the presentation is considered to be hemorrhagic [8]. Increased hematocrit levels, reflecting plasma effusion, is the main physiopathological characteristic associated with severe hemorrhagic dengue fever [8]. 
Figure 1. Admission ECG showing atrial fibrillation with a mean ventricular rate of 192 beats per minute, $\mathrm{QRS}$ axis $-10^{\circ}$ and normal ventricular repolarization.
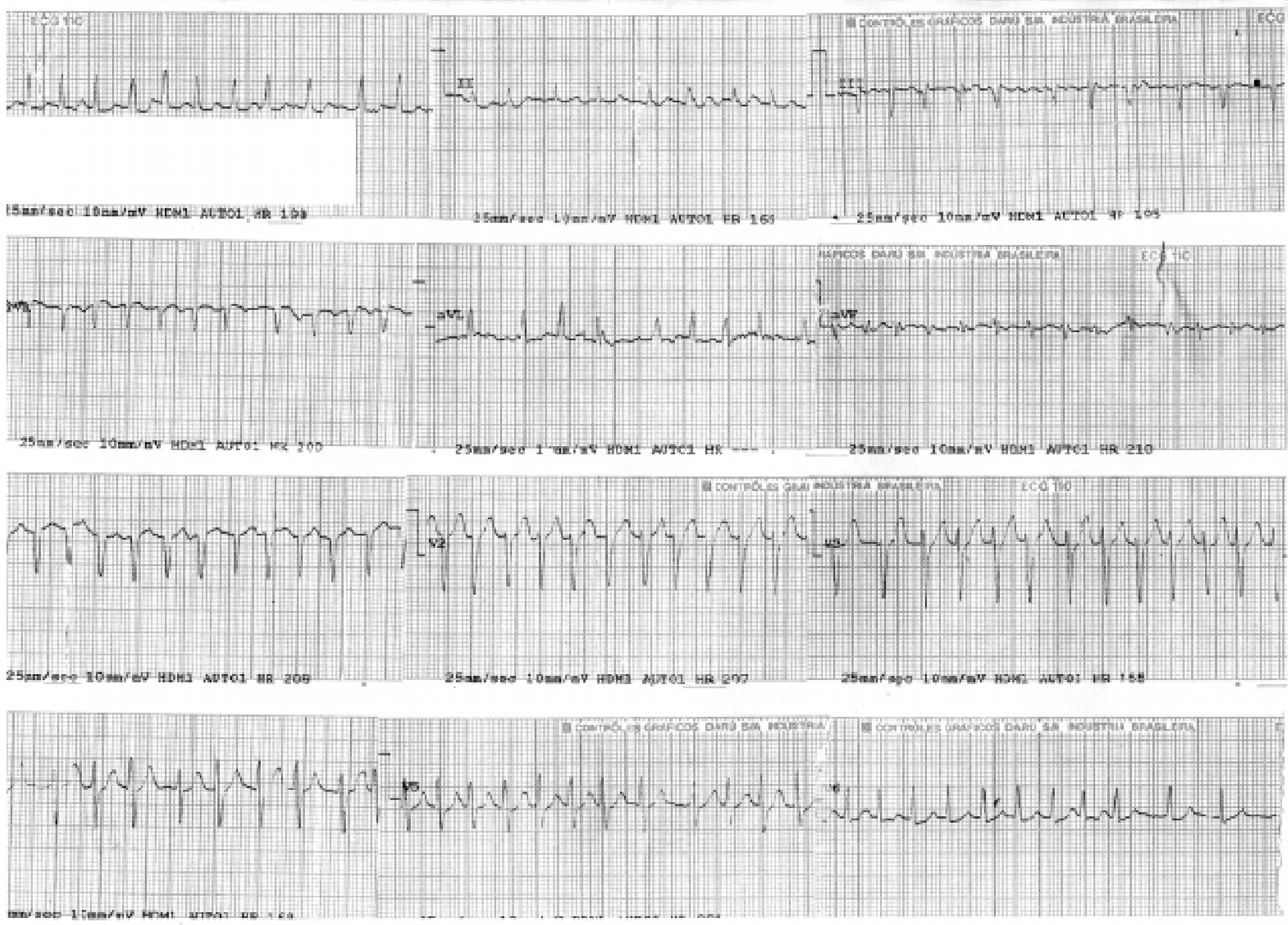
Figure 2. ECG during the second day of hospitalization, showing a normal sinus rhythm, with a heart rate of 80 beats per minute.
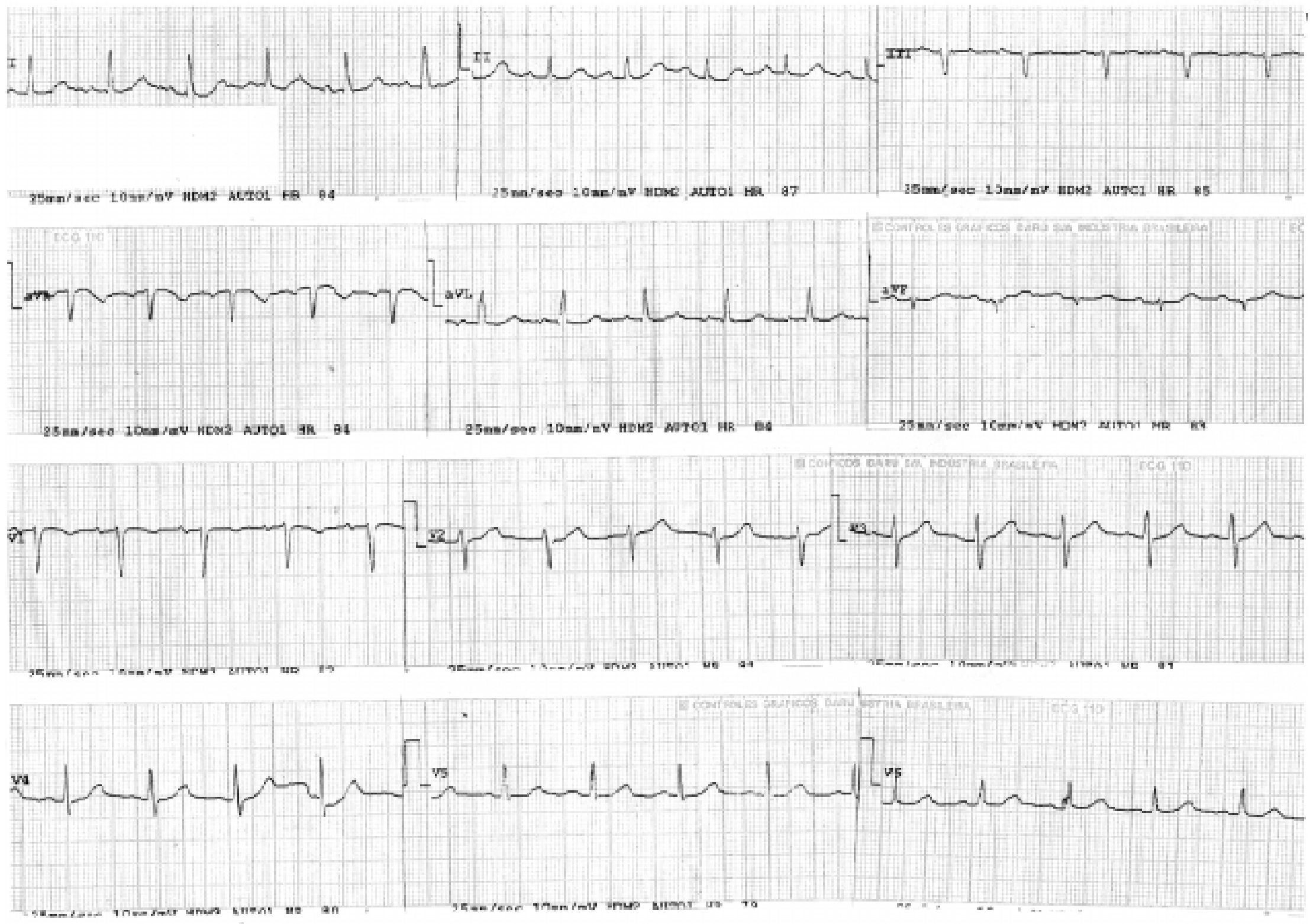
Atrial fibrillation is associated with an increased risk of thromboembolic events. Thrombi associated with atrial fibrillation most frequently arise from the left atrial appendage; its substrate is left atrial stasis and regional coagulopathy, which occur during arrhythmia. Current recommendations to reduce the risk of thromboembolisms in atrial fibrillation include, if not contraindicated, the administration of intravenous heparin or low-molecular-weight heparin in all patients with atrial fibrillation who are candidates for the restoration of sinus rhythm [7]. Hazardous hemorrhages are the most important complications in dengue fever, and they can lead to death. Logically, the use of anticoagulants increases this risk. In our patient, subcutaneous enoxiparin was initiated due to atrial fibrillation; fortunately, the patient did not present hemorrhagic complications. However, we do believe that anticoagulants should be avoided when there is suspicion of dengue fever, even when conversion of atrial fibrillation is indicated.

In conclusion, acute atrial fibrillation may occur during dengue hemorrhagic fever. In our patient, shortterm use of an anticoagulant did not lead to hemorrhagic complications. However, in cases with atrial fibrillation and suspicion of dengue, it would be prudent to use anticoagulants only if specific serological tests exclude this infection.

\section{References}

1. Gubler D.J., Clark C.G.. Community involvement in the control of Aedes aegypti. Acta Trop 1996;61:169-79.

2. Nogueira R.M., Miagostovich M.P., Schatzmayr H.G., et al. Dengue in the State of Rio de Janeiro, Brazil, 19861998. Mem Inst Oswaldo Cruz 1999;94:297-304.

3. Donegani E., Briceño J. Disturbi della conduzione atrioventricolare in pazienti colpiti da dengue emorragica. Minerva Cardioangiol 1986;34:477-80.

4. Khongphatthallayothin A., Chotivitayatarakorn P., Somchit S., et al. Mobitz type I second degree AV block during recovery from dengue hemorrhagic fever. Southeast Asian J Trop Med Public Health 2000;31:642-5.

5. Chuah S.K. Transient ventricular arrhythmia as a cardiac manifestation in dengue haemorrhagic fever: a case report. Singapore Med J 1987;28:569-72.
6. Veloso H.H., de Paola A.A.V. Fibrilação e flutter atrial. In: Atualização terapêutica. do Prado F.C., Ramos J., do Valle J.R., eds. 20 edição. São Paulo. Livraria Artes Médicas 2001:97-9.

7. Fuster V., Rydén L.E., Asinger R.W., et al. ACC/AHA/ESC Guidelines for the Management of Patients with Atrial Fibrillation: Executive Summary. A report of the American College of Cardiology / American Heart Association Task Force on Practice Guidelines and the European Society of Cardiology Committee for Practice Guidelines and Policy Conferences (Committee to Develop Guidelines for the Management of Patients with Atrial Fibrillation). J Am Coll Cardiol 2001;38:1231-65.

8. Brasil. Ministério da Saúde. Fundação Nacional de Saúde. Dengue: aspectos epidemiológicos, diagnóstico e tratamento / Ministério da Saúde, Fundação Nacional de Saúde. - Brasília: Fundação Nacional de Saúde, 2002. 20p.: il. - (Série A. Normas e Manuais Técnicos, $\left.\mathrm{n}^{\mathrm{o}} 176\right)$

9. Kochiadakis G.E., Igoumenidis N.E., Solomou M.C., et al. Efficacy of amiodarone for the termination of persistent atrial fibrillation. Am J Cardiol 1999;83:58-63.

10. Kochiadakis G.E., Igoumenidis N.E., Simantirakis E.N., et al. Intravenous propafenone versus intravenous amiodarone in the management of atrial fibrillation of recent onset: a placebo-controlled study. Pacing Clin Electrophysiol 1998;21:2475-9. 